\title{
PENGARUH TEKANAN BAHAN BAKAR TERHADAP EMISI GAS BUANG PADA MESIN K3-VE
}

\author{
${ }^{1}$ Heru Arizal, ${ }^{2}$ Ali Hasbi Ramadani, ${ }^{3}$ Ferly Isnomo Abdi \\ ${ }^{123}$ Jurusan Teknik Mesin, Fakultas Teknik, Universitas Negeri Surabaya \\ 1heruarizal@unesa.ac.id \\ 2aliramadani@unesa.ac.id \\ 3ferlyabdi@unesa.ac.id
}

\begin{abstract}
Abstrak - Salah satu penyebab polusi udara saat ini disebabkan oleh meningkatnya penggunaan kendaraan bermotor. Pengunaan teknologi juga banyak disematkan pada kendaaraan salah untuk memperbaiki kualitas emisi gas buang yang telah dihasilkan. Salah satunya adalah Teknologi EFI (Electronic Fuel Injection) yang sudah banyak disematkan pada kendaraan. Komponen yang berpengaruh pada perbaikan kualitas emisi gas buang pada EFI adalah pompa bahan bakar jenis elektronik. Tekanan bahan bakar pada Pompa elektronik dapat diatur secara manual. Penelitian ini bertujuan untuk mengetahui perubahan tekanan bahan bakar terhadap kadar emisi gas buang. Penelitian ini menggunakan metode eksperimen, dimana tekanan bahan bakar divariasi dari tekanan 50psi, 40psi, 30psi dan 20psi, serta putaran mesin yang di ubah-ubah dari putaran 800rpm, 1500rpm, 2250rpm, 3000rpm dan 3750rpm. Hasil perolehan data kita analisa dengan metode deskripsi kuntitatif. Hasil pengujian menunjukkan terjadi penurunan kadar CO paling rendah adalah sebesar 0,663\% pada tekanan bahan bakar 30psi dengan putaran mesin 3750rpm. HC juga mengalami penurunan, penuruan terendah didapatkan nilai 280ppm pada tekanan bahan bakar 20psi dan putaran mesin 3750rpm. Sedangkan $\mathrm{CO}_{2}$ mengalami kenaikan, kenaikan tertinggi sebesar 13,33\% dicapai pada tekanan bahan bakar 20psi dan putaran mesin 3750rpm.
\end{abstract}

Kata Kunci- EFI; Tekanan Bahan Bakar; Emisi Gas Buang

Abstract- One of the causes of air pollution today is the increasing use of motorized vehicles. The use of technology has also been pinned on many wrong vehicles to improve the quality of the exhaust emissions that have been produced. One of them is EFI (Electronic Fuel Injection) technology which has been embedded in many vehicles. The component that has an effect on improving the quality of exhaust emissions at EFI is an electronic fuel pump. The fuel pressure on the electronic pump can be adjusted manually. This study aims to determine changes in fuel pressure on exhaust gas emission levels. This research uses an experimental method, where the fuel pressure is varied from the pressure of 50psi, 40psi, 30psi and 20psi, and the engine speed is varied from 800rpm, 1500rpm, 2250rpm, 3000rpm and 3750rpm. The results of the data obtained are analyzed using the quantitative description method. The test results showed that there was a decrease in the lowest CO level of 0.663\% at 30psi fuel pressure with 3750rpm engine speed. HC also experienced a decrease, the lowest decrease was obtained in the value of 280ppm at 20psi fuel pressure and 3750rpm engine speed. While CO2 has increased, the highest increase of $13.33 \%$ was achieved at 20psi fuel pressure and 3750rpm engine speed.

Keywords - EFI; Fuel Pressure; Exhaust gas emissions,

\section{PENDAHULUAN}

Mobil merupakan transportasi darat yang paling digemari oleh banyak orang digunakan orang untuk berpindah tempat. Perkembangan mobil saat ini sangat pesat, baik dari segi mesinnya, chasis, maupun tingkat keselamatan dan kenyamanan. Mobil dengan mesin berbahan bakar bensin saat ini sudah di dukung tenologi yang sangat canggih. Pada jaman dahulu kita mengenal dengan karburator sebagai salah satu komponen pada system bahan bakar konvensional. Saat ini karburator sudah tidak digunakan untuk mobil-mobil baru yang diproduksi oleh perusahaan. Karburator adalah system bahan bakar konvensional yang saat ini sudah banyak digantikan oleh system bahan akar injeksi.

Salah satu kelemahan dari penggunaan karburator adalah tidak bisa melakukan penyesuaian sendiri untuk campuran udara dan bahan bakar terhadap perubahan tekanan udara, temperature, kelembapan sehingga bahan bakar lebih boros dan emisi gas buang yang kurang bagus.

EFI adalah merupakan teknologi terbaru dalam system bahan bakar pada mesin bensin. Terdapat kompenen yang bernama ECU (Electronic Control Unit) yang mengatur waktu dan banyaknya bahan bakar yang diinjeksikan kedalam ruang silinder berdasarkan sumber informasi dari beberapa sensor yang terkait. Campuran udara dan bahan bakar yang sesuai akan menghasilkan emisi gas buang yang ramah terhadap lingkungan, daya motor akan menjadi optimal, serta konsumsi bahan bakar yang rendah.

Pompa bahan bakar adalah salah satu komponen dari system bahan injeksi. Pompa ini berfungsi untuk menyalurkan serta memberikan tekanan pada bahan bakar sebelum menuju injektor. Apabila pompa bahan bakar bermasala maka akan mempengaruhi kerja dari mesin. Pompa bahan bakar harus 
dapat mengalirkan bahan bakar sesuai dengan tekanan spesifikasinya.

Kualitas udara di lingkungan telah dicemari oleh gas buang dari kendaraan bermotor. Gas buang tersebut adalah sisa gas hasil proses pembakaran yang di buang ke udara bebas melalui mufler. Pembakaran yang tidak sempurna akan menghasilkan emisi gas buang yang kurang baik. Ada beberapa strategi untuk memperbaiki kualitas emisi gas buang, salah satunya adalah membuat campuran udara dan bahan bakar menjadi homogen serta dengan perbandingan 14,7 : 1 . Jumlah penginjeksian bahan bakar dipengaruhi oleh beberapa hal yaitu lamanya penyemprotan dan tekanan bahan bakar.

Pratomo Setyadi dan Hendarko Ghany Styawan (2017) dalam penelitiannya menyebutkan jika tekanan bahan bakar dinaikkan sebesar 3,5bar terdapat penurunan kadar $\mathrm{O}_{2}$ serta kenaikan kadar $\mathrm{CO}, \mathrm{CO}_{2}$ dan $\mathrm{HC}$. Muhammad Arsyad Habe, A.M Anzarih, \& Yosrihard (2011) dalam penelitiannya menyimpulkan bahwa pada kendaraan dengan system bahan bakar injeksi menghasilkan kadar emisi gas buang lebih rendah dibandingkan dengan mesin yang menggunakan karburator. Pendapat dari Amrullah (2018) menyimpulkan penggunaan pertamax menghasilkan emisi gas buang lebih baik daripada premium.

Penelitian terdahulu sangat menarik untuk diteliti lebih lanjut tentang emisi gas buang terhadap mesin injeksi dengan bahan bakar pertamax. Penelitian yang terdahulu belum mencakup penurunan tekanan bahan bakar pada mesin injeksi terhadap hasil emisi gas buang. Untuk itu dilakukan penelitian emisi gas buang pada mesin K3-VE jika tekanan bahan bakar diturunkan.

\section{METODE}

Pada penelitian ini menggunakan metode eksperimen dimana reaksi emisi gas buang jika terjadi perubahan putaran mesin serta tekanan bahan bakar. Pada Mesin K3-VE terdapat komponen pressure regulator dan pulsation damper yang berfungsi mempertahankan tekanan bahan bakar tidak melebihi tekanan standar. Oleh karena itu pada penelitian ini tekanan bahan bakar dilakukan penurunan dari tekanan standar. Tekanan bahan bakar diatur dari tekanan standar (50psi), 40psi, 30psi, 20psi, pada masing-masing 800rpm, 1500rpm, 2250rpm, 3000rpm, dan 3750rpm. Hasil data berupa nilai rata-rata percobaan, dimana percobaan dilakukan dalam sebanyak tiga kali. Unit engine stand K3-VE serta exhaust gas analizer merupakan media yang kita gunakan dalam penelitian ini.

Tahap pengujian ada hal yang harus kita lakukan :

1. Melakukan tune-up

2. Menyalakan mesin sampai pada kondisi suhu kerja

3. Menyalakan Gas Analizer

4. Memasang gas probe pada knalpot

5. Mengatur tekanan bahan bakar

6. Mengatur kecepatan mesin

7. Mencatat emisi gas buang $\mathrm{CO}, \mathrm{CO}_{2}, \mathrm{HC}$

8. Mengulangi pengujian dengan sesuai tekanan dan putaran yang diharapkan dan dilakukan sebanyak 3 kali percobaan

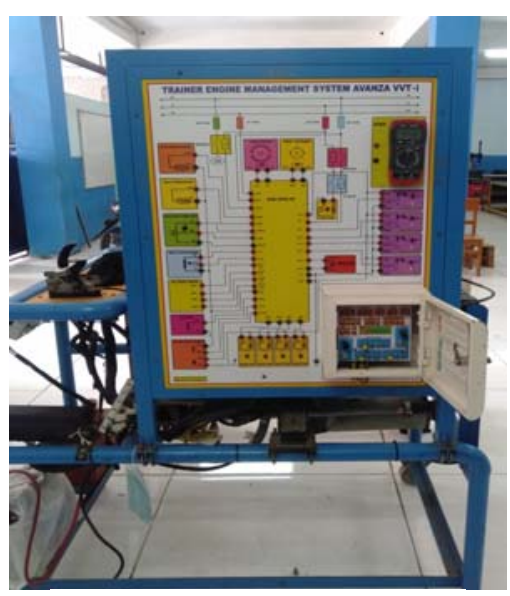

Gambar 1 Engine Stand K3-VE

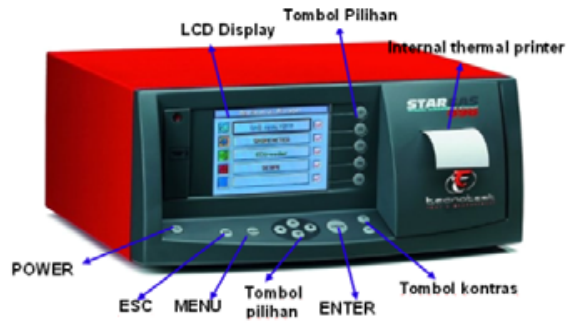

Gambar 2 Exhaus Gas Analyzer

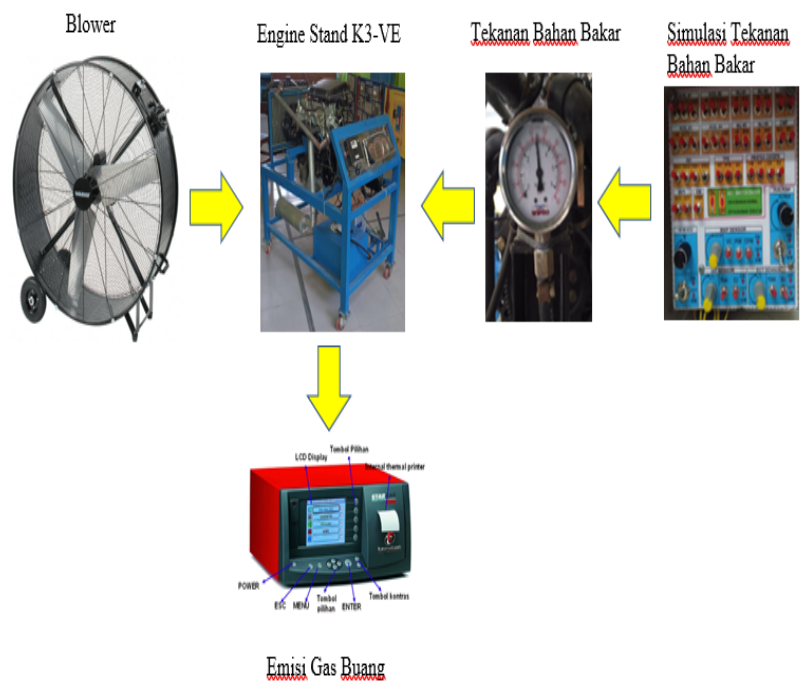

Gambar 3 Skema Pengujian 


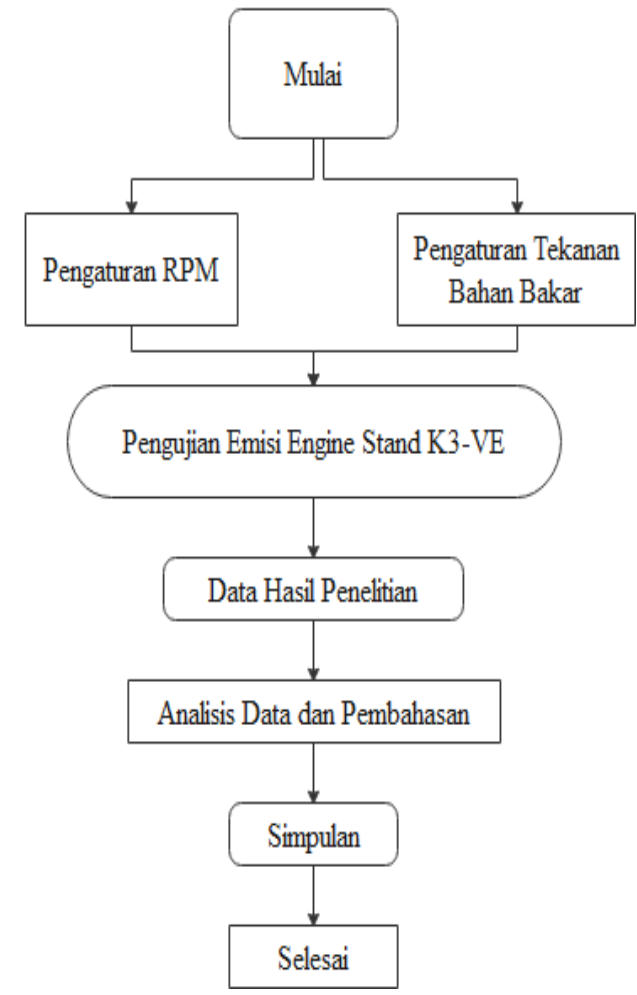

Gambar 4 Diagram Alir Model Penelitian

Beberapa variabel yang digunakan dalam penelitian adalah sebagai berikut :

1. Variabel Bebas

- Tekanan pompa bahan bakar (10psi, 15psi, 20psi,25psi,30psi)

- Putaran mesin (750rpm, 1500rpm, 2250rpm, 3000rpm, 3700rpm)

2. Variabel Kontrol

- $\quad$ Suhu mesin $\left(85^{\circ} \mathrm{C}-96^{\circ} \mathrm{C}\right)$

- Suhu udara sekitar $\left(32^{\circ} \mathrm{C}-34^{\circ} \mathrm{C}\right)$

- Jenis bahan bakar (Pertamax)

3. Variabel Tetap

- $\quad$ Nilai parameter emisi gas buang

Hasil pengambilan data, kemudian di cari nilai rata-rata dari 3 kali percobaan pengujian. Dari rata-rata pengujian tersebut dilakukan analisa lebih mendalam dan penarikan kesimpulan dari penelitian

\section{CO (Carbon Monoksida)}

\section{HASIL DAN DISKUSI}

Pembakaran yang tidak sempurna akan menghasilkan karbon monoksida dimana campuran bahan bakar lebih banyak dibandingkan dengan udara. CO sangat berbahaya bagi manusia dikarenakan senyawa ini tidak berbau serta tidak memiliki warna yang akan mengakibatkan rasa pusing maupun mual. Hasil emisi gas buang dengan parameter $\mathrm{CO}$ (carbon monoksida) dengan memvariasi tekanan bahan bakar dan putaran mesin diperoleh data seuai pada Tabel 1 .
Tabel 1: Emisi gas CO pada variasi tekanan dan rpm.

\begin{tabular}{|c|c|c|c|c|}
\hline \multirow{2}{*}{ RPM } & \multicolumn{4}{|c|}{ TEKANAN } \\
\cline { 2 - 5 } & $50 \mathrm{psi}$ & $40 \mathrm{psi}$ & $30 \mathrm{psi}$ & $20 \mathrm{psi}$ \\
\hline 800 & 1,640 & 1,204 & 0,893 & 0,729 \\
\hline 1500 & 1,632 & 1,003 & 0,884 & 0,784 \\
\hline 2250 & 1,529 & 0,958 & 0,804 & 0,808 \\
\hline 3000 & 1,482 & 0,930 & 0,729 & 0,847 \\
\hline 3750 & 1,335 & 0,886 & 0,663 & 0,892 \\
\hline
\end{tabular}

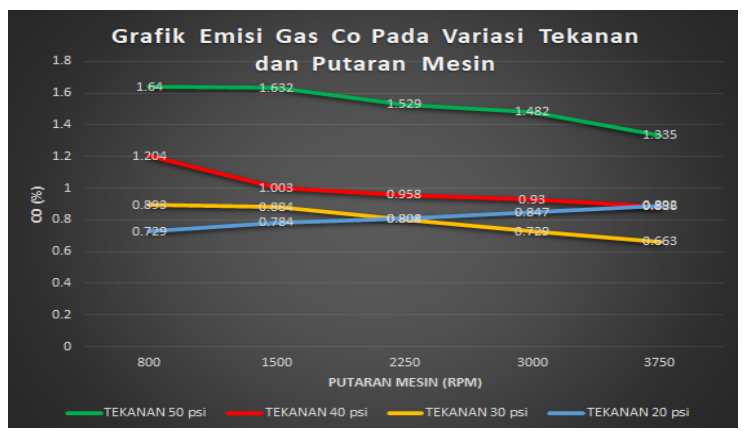

Gambar 5 Grafik Hubungan Emisi Gas Buang CO

Terhadap Variasi Tekanan Bahan Bakar dan Putaran Mesin Dari Tabel 1, menunjukkan kadar CO hasil pembakaran paling kecil sebesar 0,663\% pada tekanan bahan bakar 30psi serta di putaran mesin $3750 \mathrm{rpm}$. Nilai kadar CO pada posisi paling tinggi yaitu sebesar $1,640 \%$ pada posisi tekanan bahan bakar 50 psi dan putaran mesin $800 \mathrm{rpm}$. Nilai ambang CO adalah 1,5\%, kadar $\mathrm{CO}$ semakin kecil maka semakin baik pula proses pembakaran. Perolehan data di atas dapat kita analisa bahwa tekanan bahan bakar diperkecil menghasilkan CO semakin baik, akan tetapi pada posisi tekanan di 20 psi nilai CO kembali naik. Pada putaran mesin 1500rpm terjadi penurunan kadar CO yang paling besar dari tekanan 50psi menuju 40psi, yaitu sebesar $0,571 \%$

\section{$\underline{\mathrm{CO}}_{2}$ (Carbon Dioksida)}

Nilai $\mathrm{CO}_{2}$ juga mengalami perubahan di setiap perubahan tekanan bahan bakar. Data $\mathrm{CO}_{2}$ dalam pengujian ini dapat kita lihat pada Tabel 2. $\mathrm{CO}_{2}$ merupakan salah satu hasil pembakaran yang sempurnah, jika nilai kadar $\mathrm{CO}_{2}$ semakin besar dapat kita simpulkan proses pembakarannya semakin baik. Tabel 2 menunjukkan nilai $\mathrm{CO}_{2}$ paling rendah 8,45 pada putaran mesin $800 \mathrm{rpm}$ dengan tekanan bahan bakar senilai 50psi. Nilai $\mathrm{CO}_{2}$ paling tinggi/13,33 diperoleh pada saat tekanan bahan bakar di 20psi serta kecepatan mesin sebesar 370rpm. Dari data di atas dapat kita lihat nilai kadar $\mathrm{CO}_{2}$ semakin tinggi saat tekanan bahan bakar diturunkan serta putaran mesin diperbesar. 
Tabel 2: Emisi gas $\mathrm{CO}_{2}$ pada variasi tekanan dan rpm

\begin{tabular}{|c|c|c|c|c|}
\hline \multirow{2}{*}{ RPM } & \multicolumn{4}{|c|}{ TEKANAN } \\
\cline { 2 - 5 } & $50 \mathrm{psi}$ & $40 \mathrm{psi}$ & $30 \mathrm{psi}$ & $20 \mathrm{psi}$ \\
\hline 800 & 8,45 & 11,67 & 12,66 & 12,98 \\
\hline 1500 & 9,90 & 11,93 & 12,82 & 13,13 \\
\hline 2250 & 10,70 & 12,29 & 12,96 & 13,26 \\
\hline 3000 & 11,20 & 12,50 & 13,02 & 13,29 \\
\hline 3750 & 12,18 & 12,71 & 13,19 & 13,33 \\
\hline
\end{tabular}

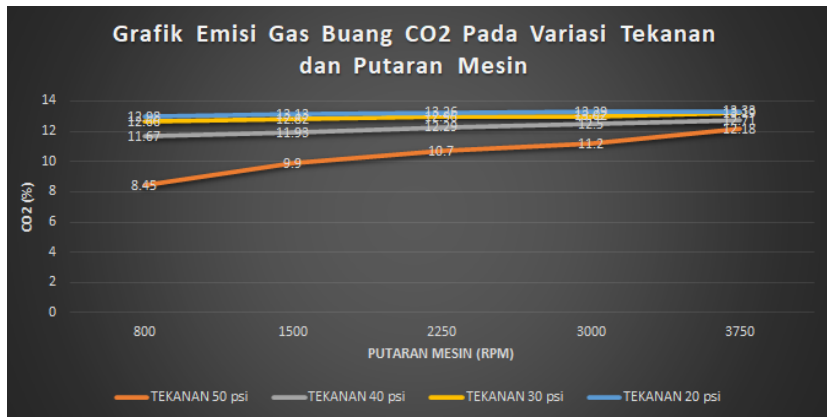

Gambar 6 Grafik Hubungan Emisi Gas Buang CO2

Terhadap Variasi Tekanan Bahan Bakar dan Putaran Mesin

\section{HC (Hidro Carbon)}

HC merupakan salah satu unsur yang dihasilkan oleh mesin pembakaran dalam. Senyawa Hidro Carbon terjadi karena bahan bakar telah terbuang sebelum sempat terbakar. Senyawa HC akan berdampak pada manusia yaitu mata terasa pedih, ternggorokan akan sakit serta mengakibatkan penyakit kanker dan paru-paru. Nilai HC dari percobaan pengurangan tekanan bakan bakar dapat kita dilihat pada Tabel 3 .

HC salah satu unsur yang berbahaya untuk manusia. Besarnya nilai HC diakibatkan adanya bahan bakar yang belum terbakar telah keluar dari mesin. Nilai HC yang dihasilkan oleh mesin pembakaran dalam bensin dikatakan baik apabila nilainya kurang dari 500ppm apabila mesin tidak menggunakan CC (Catalytic Converter). Nilai HC paling tinggi didapatkan pada putaran mesin $800 \mathrm{rpm}$ dan tekanan 50psi yaitu sebesar 681ppm. Sedangkan nilai HC paling kecl didapatkan pada posisi putaran mesin 3750 dan tekanan bahan bakar di 20 psi, menghasilkan HC senilai 280ppm.

Tabel 3: Emisi gas HC pada variasi tekanan dan rpm

\begin{tabular}{|c|c|c|c|c|}
\hline \multirow{2}{*}{ RPM } & \multicolumn{4}{|c|}{ TEKANAN } \\
\cline { 2 - 5 } & $50 \mathrm{psi}$ & $40 \mathrm{psi}$ & $30 \mathrm{psi}$ & $20 \mathrm{psi}$ \\
\hline 800 & 681 & 592 & 521 & 473 \\
\hline 1500 & 597 & 544 & 479 & 473 \\
\hline 2250 & 553 & 503 & 445 & 456 \\
\hline 3000 & 511 & 467 & 389 & 438 \\
\hline 3750 & 496 & 422 & 327 & 280 \\
\hline
\end{tabular}

Heru Arizal: Pengaruh Tekanan Bahan Bakar . . . .

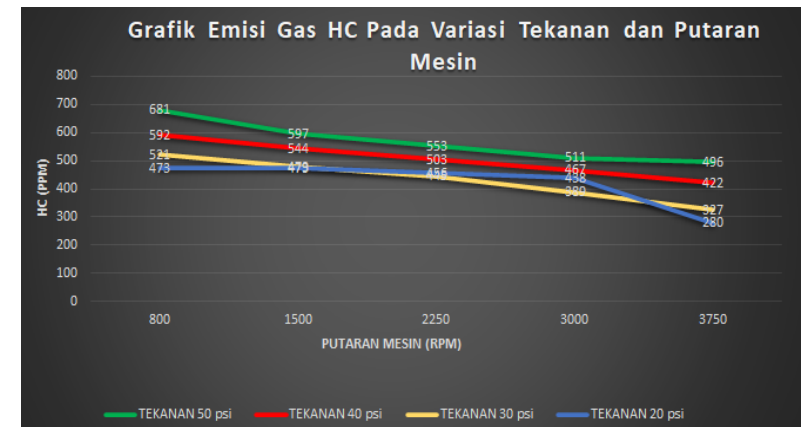

Gambar 7 Grafik Hubungan Emisi Gas Buang HC

Terhadap Variasi Tekanan Bahan Bakar dan Putaran Mesin

Kadar emisi gas buang $\mathrm{CO}$ dan $\mathrm{HC}$ mayoritas mengalami penurunan saat dilakukan penurunan tekanan bahan bakar. Penurunan kadar $\mathrm{CO}$ dan $\mathrm{HC}$ ini mengakibatkan kualitas emisi gas buang hasil pembakan semakin baik. Sedangkan kadar emisi gas buang $\mathrm{CO}_{2}$ mengalami peningkatkan. Peningkatan $\mathrm{CO}_{2}$ ini juga mengakibatkan kualitas emisi gas buang semakin baik.

Pengujian data menunjukkan nilan perbaikan kadar emisi gas buang yang dihasilkan oleh mesin K3-VE apabila dilakukan penurunan tekanan bahan bakar. Nilai terbaik dari kadar CO diperoleh pada putaran 3750rpm dengan tekanan bahan bakar 30psi yaitu sebesar 0,663\%. Dilihat pada putaran yang sama akan tetapi tekanannya yang diturunkan selalu menimbulkan penurunan kadar $\mathrm{CO}$ artinya penurunan tekanan bahan bakar berakibat turunnya kadar $\mathrm{CO}$ yang dihasilkan oleh mesin K3-VE. Penurunan kadar CO disebabkan perbandingan bahan bakar yang samakin ideal atau sesuai dengan kebutuhan. Artinya jumlah bahan bakar yang masuk kedalam ruang silender volumenya berkurang, sehingga perbandingan udara dan bahan bakar menjadi kurus.

$\mathrm{CO}_{2}$ merupakan salah satu indikator usur pembakar yang sempurna. Semakin besar kadar $\mathrm{CO}_{2}$ maka semakin baik pula proses pembakarannya. Kadar $\mathrm{CO}_{2}$ dalam pengujian ini diperoleh paling baik adalah pada putaran $3750 \mathrm{rpm}$ dan tekanan 20psi yaitu sebesar $13,33 \%$. Berdasarkan data yang diperoleh, semakin turun tekanan bahan bakar maka semakin tinggi kadar $\mathrm{CO}_{2}$. Pada putaran stationer terjadi penurunan paling besar sekitar 4,53 point dari tekanan standar, dari data tersebut pada putaran stationer dan tekanan standar memiliki perbandingan yang gemuk sehingga ada pembakaran yang belum sempurna. Semakin rendah tekanan bahan bakar menunjukkan bahwa perpaduan yang semakin seimbang antara udara dan bahan bakar akan mengakibatkan pembakaran semakin sempurna.

$\mathrm{HC}$ adalah emisi gs buang yang disebabkan adanya bahan bakar yang keluar dari mesin sebelum ikut terbakar. Semakin kecil nilai kadar ppm yang dihasilkan oleh mesin maka semakin baik kadar emisi gas buang. Pada penelitian ini didapatkan nilai paling baik adalah 280ppm pada putaran $3750 \mathrm{rpm}$ dan tekanan 20psi. Tekanan yang berkurang menyebabkan volume bahan akar yang diinjeksikan semakin berkurang, mengakibatkan perbandingan semakin kurus. Perbandingan semakin kurus ini mengakibatkan bahan bakar 
lebih mudah ikut terbakar, sehingga nilai HC semakin kecil. Setiap penurunan tekanan pada rpm yang sama selalu mengakibatkan penurunan kadar HC, sehingga emisi yang dihasilkan semakin baik.

Pada penelitian Mohamad Sanusi menyampaikan nilai terendah HC pada kendaraan injeksi di putaran $3000 \mathrm{rpm}$ dengan bahan bakar pertamax yaitu sebesar 498 ppm dan nilai $\mathrm{CO}$ adalah 0,65 . Perubahan tekanan bahan bakar pada putaran 3000rpm menghasilkan CO terendah adalah 0,729 pada tekanan 30psi sedangkan HC paling rendah adalah 389 pada tekanan 30psi. Dari perbandingan tersebut dapat kita analisa terjadi perbaikan nilai $\mathrm{HC}$ jika tekanan bahan makar di turunkan pada tekanan 30psi. Akan tetapi pada CO tidak terjadi perubahan jika mengacu pada data penelitian Mohamad Sanusi.

Muhammad Arsyad Habe menyimpulan kadar CO dan HC pada penelitinnya menggunakan mesin EFI menghasilkan nilai rata-rata sebesar $2,75 \%$ dan $387 \mathrm{ppm}$. Dibandingkan dengan penelitian perubahan tekanan rata-rata didapatkan nilai $\mathrm{HC}$ dan CO 526,41ppm dan 1,0315\%. Dari perbandingan data tersebut nilai $\mathrm{CO}$ terjadi selisih 1,7 dari penelitian muhammad arsyad sedangkan untuk nilai HC terdapat selisih 139 poin.

\section{KESIMPULAN}

Proses hasil sisa pembakaran kendaraan bermotor disebut emisi gas buang. Kualitas emisi gas buang dipengaruhi oleh beberapa faktor, misalnya jenis bahan bakar, perbandingan jumlah bahan bakar dan udara. Jumlah bahan bakar yang disemprotkan dipengaruhi oleh berapa lama waktu penginjeksian dan tekanan bahan bakar. Pada penelitian ini menunjukkan semakin menurun tekanan bahan bakar pada putaran mesin yang sama tejadi perbaikan kualitas emisi gas buang $\mathrm{CO}, \mathrm{HC}$ dan $\mathrm{CO}_{2}$

Di setiap penurunan tekanan bahan bakar pada rpm yang sama selalu terjadi penurunan kadar CO. Pada putaran stationer terjadi penurunan kadar $\mathrm{CO}$ dengan selisih 0,911 point antara tekanan 50psi dengan 20psi. Pada HC terjadi penurunan terbesar dengan nilai 216ppm pada putaran 3750rpm. Berlaku juga kondisi HC terhadap tekanan bahan bakar dimana tekanan bahan bakar semakin berkurang maka $\mathrm{HC}$ yang dihasilkan semakin kecil/baik. Kadar $\mathrm{CO}_{2}$ selalu terjadi kenaikan nilai prosentasenya di setiap penurunan tekanan bahan bakar walau di setiap putaran mesin. $\mathrm{CO}_{2}$ terjadi kenaikan maksimal 4,53 point pada putaran stationer.

Kualitas emisi gas buang yang semakin baik pada setiap penurunan tekanan bahan bakar disebabkan perbandingan udara dan bahan bakar yang sesuai dengan spesifikasi pembakaran sempurna yaitu 14,7 : 1. Dimana setiap penurunan tekanan bahan bakar menyebabkan jumlah bahan bakar yang diinjeksikan semakin berkurang..

\section{REFERENSI}

[1] Amrullah, Sungkono, Eko Prastianto. 2018. Analisis Pengaruh Penggunaan Bahan Bakar Premium dan Pertamax Terhadap Prestasi Mesin. Jurnal Teknologi : Vol 18 No 1

[2] Arifin, Z, dan Sukonco. 2009. Pengendalian Polusi Kendaraan. Bandung: Alfabeta
[3] Bakeri, Mustafa, Akhmad Syarief, Ach Kusairi. 2012. Analisa Gas Buang Mesin Berteknologi EFI dengan Bahan Bakar Premium. Info Teknik : Volume 13 No 1

[4] Cappenberg, Audri D. 2014. Studi Tentang Berbagai Tipe Bahan Bakar Terhadap Prestasi Mesin Mobil Toyota XXX. Jurnal Konversi Energi dan Manufaktur UNJ : Edisi Terbit III

[5] Hartono, Dwijo, Marthen Paloboran, Bambang Sudarmanta. 2017. Studi Eksperimental Pengaruh Mapping Waktu Pengapian dan Mapping Durasi Injeksi Serta Rasio Kompresi Terhadap Performansi dan Emisi Gas Buang Engine Honda CBR 150R Berbahan Bakar E50. Jurnal Teknik Mesin Indonesia : Vol 12 No 2

[6] Habe, Muhammad Arsyad, A.M Anzarih, Yosrihard Basongan. 2011. Analisa Emisi Gas Buang Mesin EFI Dan Mesin Konvensional Pada Kendaraan Roda Empat. Jurnal Teknik Mesin Sinergi : Vol 9.

[7] Hasan, Hanapi, Bambang Sudarmanta, Marthen Paloboran. 2017. Influence Of The Compression Ratio and Injection On Performance and Emission Engine Type Flexible Fuel Engine $150 \mathrm{cc}$ Fueled Bioethanol E70. Journal Of Engineering : Vol 3 No 3

[8] Hendri, M., Tinton, D., \& Dalmasius, G. (2017). Teknologi Sensor Otomotif. Bandung: Rekayasa Sains

[9] Ibrahim, Husin, A.H Sebayang, Rahmawati. Kinerja Mesin dan Emisi Gas Buang Mesin Bensin Menggunakan Bahan Bakar Campuran Pertalite-Bioetanol Tandan Kosong Kelapa Sawit. 2018. PISTON Jurnal Ilmiah Teknik Mesin Fakultas Teknik UISU : Vol 2 No 2

[10] Pratomo, Hendarko. 2017. Pengaruh Kenaikan Tekanan Pompa Bahan Bakar Terhadap Performa Sepeda Motor Honda 125 CC Injeksi Menggunakan Pompa Bahan Bakar Pneumatik. Jurnal Seminar Nasional Sains dan Teknologi Universitas Muhammadiyah Jakarta

[11] Prayoi, Y, Syaiful, N Sinaga. 2018. Performance and Exhaust Gas Emission Of Gasoline Engine Fueled By Gasoline, Acetone and Wet Methanol Blends. International Converence on Technology and Vocation Teacher

[12] Pulkrabek, Willard W. 1997. Engineering Fundamentals Of the Internal Combustion Engine. New Jersey: Prentice-Hall, Inc

[13] Sanusi, Mohamad, Hendra Uloli, Yasser Arafat. 2019. Pengaruh Variasi Jenis Bahan Bakar Terhadap Emisi Gas Buang Pada Sepeda Motor VIXION 155cc VVA Tipe Injeksi Tahun 2018. SimanTECH

[14] Siswantoro, Lagiyono, Siswiyati. 2012. Analisa Emisi Gas Buang Kendaraan Bermotor 4 Tak Berbahan Bakar Campuran Premium dengan Variasi Penambahan Zat Aditif. Jurnal Engineering: Vol 3 No 2

[15] Sugiarto, Totok. 2013. Analisa Kerja Manifold Absolute Pressure (MAP) dan Ladar Kandungan Emisi Gas Buang Yang Dihasilkan Pada Motor Bendin Dengan Sistem Injeksi Elektronik Type D-EFI. Jurnal Elektron : Vol 5 No 2

[16] Syarifuddin, Ahmad, MKS Tony Suryono Utomo, Syaiful. 2016. Performa dan Emisi Gas Buang Mesin Bensin dengan Sistem EGR Panas Pada Campuran Bahan Bakar Premium dan High Purity Methanol. Jurnal Mekanikal : Vol 7 No 1

[17] Wahyu, H., \& Riri, S. (2017). Teknologi Baru Motor Bensin. Bandung: Alfabeta.

[18] Wahyu, Mujahid, Hadi Rahmad. 2018. The Exhaust Gas Emission Test On Honda Brio Satya With Variation Of Fuel and Rotation Engine. VANOS Journal Of Mechanical Engineering Education : Vol 3 